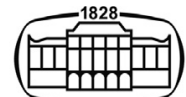

AKADÉMIAI KIADÓ

\title{
The first wave of the COVID-19 pandemic in Southern Hungary: Epidemiology, symptoms and signs
}

\section{IMAGING}

\section{ORIGINAL ARTICLE}

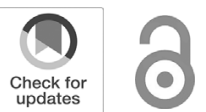

IMAGING 13 (2021) 2, 142-151

DOI: $10.1556 / 1647.2021 .00014$

\section{(C) 2021 The Author(s)}

*Corresponding author. Department of Radiology, University of Szeged,

Semmelweis Str. 6., Szeged, H-6720, Hungary.

E-mail: zsuzsanna.fejes.02@szte.hu

\section{PÉTER PALÁSTI ${ }^{1}$, ÁDÁM VISNYOVSZKI ${ }^{2}$, SÁNDOR CSIZMADIA ${ }^{3}$, MÁRIA MATÚZ ${ }^{4}$, ZSANETT SZABÓ ${ }^{2}$, EDIT HAJDÚ ${ }^{2}$, DOMINIKA VATTAY ${ }^{1}$, ANDRÁS PALKÓ ${ }^{1}$, TAMÁS ZSIGMOND KINCSES ${ }^{1}$ and ZSUZSANNA FEJES ${ }^{1 *} \odot$}

\author{
${ }^{1}$ Department of Radiology, University of Szeged, Szeged, Hunagry \\ ${ }^{2}$ Department of I. Internal Clinic, University of Szeged, Faculty of Medicine, Infectology Ward, \\ Szeged, Hungary \\ ${ }^{3}$ Affidea Diagnostics Hungary Ltd., Budapest, Hungary \\ ${ }^{4}$ Department of Clinical Pharmacy, University of Szeged, Faculty of Pharmacy, Szeged, Hungary
}

Received: September 3, 2020 • Accepted: June 22, 2021

\section{ABSTRACT}

Background: In December 2019, pneumonia caused by coronavirus Disease-19 (COVID-19) occurred in Wuhan, Hubei Province, China. Currently, COVID-19 has spread worldwide. In accordance with the restrictions of the Hungarian Government, several epidemic hospitals and centers have been established in Hungary. The first infected patient was detected on 4th March, 2020 in our country, who was not a Hungarian citizen. The first patient died of pneumonia caused by COVID-19 was on $15^{\text {th }}$ March. The Hungarian epidemic curve is flattened and more prolonged. We aimed to report our computer tomography (CT) findings in correlation with clinical status in patients with COVID-19 infection.

Material and methods: All patients with laboratory-identified Severe Acute Respiratory Syndrome Coronavirus 2 (SARS-CoV-2) infection by real-time polymerase chain reaction (PCR) and who underwent chest CT were collected between March 26, 2020, and April 20, 2020, in our hospital. In our centre we had 107 PCR confirmed COVID-19 positive patients in this period. 52 patient (male: female 1:2, average age: 67.94) were admitted to our central epidemic hospital, according to their complains: fever, dyspnoea, hypoxaemia, altered mental status, comorbidity, sepsis or if patient isolation could not be performed. In case of every patient we took blood test, nasopharyngeal sample and a chest CT without contrast agent. In our CT report we used a score system to characterize the severity.

Results: The majority of infected patients had a history of exposure in nursing homes and mostly presented with fever and cough. The present study confirmed the findings about results of other researches. The COVID-19 pneumonia affected the elderly patients, caused hypoxia, cough and sepsis. On the CT scan, typical signs were seen in the cases of PCR confirmed patients.

Conclusion: The limitations of the present study include the low number of patients. Collectively, our results appear consistent with previous studies. Chest CT examination plays an important role in the diagnosis and estimation of the severity of the novel coronavirus pneumonia. Future research should examine strategically the features of the Hungarian population.

\section{KEYWORDS}

COVID-19, computer tomography, ground glass opacity, SARS-CoV-2

\section{Introduction}

In December 2019, an outbreak of viral pneumonia of unknown aetiology emerged from Wuhan city, Hubei Province, China [1]. 
The virus was identified on the $7^{\text {th }}$ of January, 2020 . Genetic characterization revealed that the pathogen in question is a +ssRNA virus from the order of Nidovirales and belongs to the family of Coronaviridae, more specifically the subfamily of Coronavirinae, Betacoronavirus genera [2]. The virus is phylogenetically $89-98 \%$ identical to SARSrelated-CoV strains found in bats and $78-82 \%$ to SARS-CoV found in humans, hence the name SARS-CoV-2. The disease caused by the virus was named COVID-19 [3,4]. On the $11^{\text {th }}$ of March, 2020, the WHO declared the SARS-CoV-2 outbreak a pandemic [5].

The focus of this study is to examine the effects of COVID-19 among the Hungarian population. The collected data of the specific characteristics of pneumonia caused by the virus as well as other manifestations would allow for a comparison of the spectrum of presentations between Hungary and other countries. The overall goal of this research is to compare different indicators, such as blood tests and CT finding, to see, if any laboratory parameters could potentially predict the grade of lung involvement. This would allow for early recognition of whether a patient needs urgent, early CT imaging and close monitoring with CT follow-ups.

\section{Aetiology, pathogenesis, symptoms and complications}

Many hypotheses have been made based on phylogenetic studies, but it has become accepted that SARS-CoV-2 may have originated from bats and can be transmitted to humans by zoonosis, reinforcing the fact that the virus could replicate in the organoid of bats [6]. Transmission between humans can occur by aerosol and respiratory droplets, while feco-oral transmission is speculated but unproven [3]. There is indirect evidence for feco-oral transmission, such as the ability of SARS-CoV-2 to infect human intestinal epithelial cells in vitro, while another study has identified messenger RNA (sgRNA) from stool samples, which would indicate the virus' ability to replicate in the gastrointestinal tract $[6,7]$.

The coronavirus can reach the upper and lower respiratory tract directly or indirectly, typically causing symptoms in these regions. Among the coronaviruses, SARS$\mathrm{CoV}$, MERS-CoV and SARS-CoV-2 are able to infect the lower respiratory tract [1]. SARS-CoV-2 was successfully isolated and subgenomic sgRNA was detected from throat swabs, which served as evidence for active upper airway replication, while also explaining, why pharyngeal shedding and transmission are more effective, than that of SARS-CoV in cases where symptoms are mild or non-detectable [2, 3]. In the later stages of the disease, SARS-CoV-2 infection is very similar to SARS-CoV, with a well-known pathogenesis, where the infection triggers an inflammatory process. The patient's response highly influences the clinical picture and radiological image and ultimately the course of the disease [1].

The virus will first bind to a spike protein on cells, which express angiotensin-converting enzyme 2 (ACE2), such as airway epithelial cells, alveolar epithelial cells, vascular endothelial cells and macrophages in the lung. In addition, cellular serine protease (TMPRSS2) is required for proper binding. The protease cleaves the spike protein, allowing it to bind to cells with greater affinity and facilitate entry. Infection results in downregulation of the ACE2 receptor, directly affecting the renin-angiotensin system (RAAS), altering blood pressure, fluid/electrolyte balance and increasing inflammation and vascular permeability [1].

For the reasons described above, the SARS-CoV-2 infection causes secondary viraemia, followed by an extensive attack on ACE2-expressing organs, such as the heart, kidneys, gastrointestinal tract and peripheral vasculature [2].

SARS-CoV-2 is a cytopathic virus, which means, that the replication cycle is associated with cell damage or death, the latter occurring as a form of programmed cell death (pyroptosis) with intense inflammation. Pyroptosis results in a local immune response that will manifest as interstitial pneumonia in the lungs. Cytokines, proinflammatory proteins (IL-1 $\beta$, IL-6, IFN $\gamma$, MCP1, and IP-10) and DAMPs, PRPs released during inflammation increase vascular permeability. T-cells, monocytes and macrophages will be recruited and pathogens eliminated, resulting in resolution of the disease in most cases [1].

Unfortunately, in the remainder of occurrences, the dysfunctional immune response can result in severe lung damage and a systemic inflammatory response [1].

Laboratory tests were performed on all patients admitted. A complete blood count, metabolic panel, blood glucose level, coagulation panel, serum C-reactive protein, procalcitonin, lactate dehydrogenase (LDH) and cardiac biomarkers (CK, CK-MB, Troponin-T) were obtained.

The median incubation time is $4.5-5.2$ days, and $97.5 \%$ of infected patients develop symptoms by 11.5 days $[1,4]$. The most common symptoms of COVID-19 are fever, dry cough, dyspnoea, arthralgia/myalgia, headache, dizziness, nausea, vomiting and diarrhoea. In severe cases, the disease usually progresses to acute respiratory distress syndrome (ARDS) for an average of 8-9 days, accounting for $70 \%$ of COVID-19-associated mortality. A further $28 \%$ may be responsible for sepsis or a cytokine storm caused by a systemic inflammatory response [1].

The most common complications are thromboembolic events, cardiovascular complications, acute kidney injury, acute liver injury and neurologic complications. Uncommon, but severe complications include cytokine release syndrome, septic shock, disseminated intravascular coagulation (DIC) and acute respiratory failure [8-10].

\section{Diagnosis}

According to the World Health Organization (WHO), a patient is considered COVID-19 infected, if laboratory confirmation has been obtained, regardless of whether the patient is symptomatic or not.

The laboratory technique used for confirmation is a realtime reverse transcription polymerase chain reaction (RTPCR), which requires a sample, that can be collected from the upper (nasal and oropharyngeal) and lower respiratory 
tract (sputum, endotracheal aspirate, bronchoalveolar lavage). The virus can also be detected in faeces and blood [4].

\section{Clinical risk stratification}

Clinical risk stratification was calculated in accordance with Hungarian recommendations, which include four categories instead of the three used by the Chinese Centre for Disease Control and Prevention [11, 12]. These recommendations are summarized in Tables 1 and 2 .

Table 1. Recommendations of the Chinese Center for disease control and prevention

\begin{tabular}{lc}
\hline Mild & non-pneumonia \\
& mild pneumonia \\
Severe & dyspnoea
\end{tabular}

Respiratory frequency $\geq 30$

blood oxygen saturation $\leq 93 \%$ partial pressure of arterial oxygen to fraction of inspired oxygen ratio $<300$, and/or lung infiltrates $>50 \%$ within 24 $48 \mathrm{~h}$

Critical respiratory failure septic shock

and/or multiple organ dysfunction or failure

Table 2. Recommendation of the Hungarian Ministry of Human Capacities

\begin{tabular}{|c|c|}
\hline \multicolumn{2}{|r|}{ no rest or effort dyspnoea } \\
\hline Moderate & $\begin{array}{l}\text { number of breaths per minute } \\
\text { dyspnoea, tachypnoea, or } \mathrm{O} 2 \text { demand } \\
\pm \text { pneumonia on chest imaging }\end{array}$ \\
\hline Severe & dyspnoea \\
\hline & $\begin{array}{c}\text { Respiratory frequency } \geq 30 \\
\text { blood oxygen saturation } \leq 93 \% \\
\text { partial pressure of arterial oxygen to } \\
\text { fraction of inspired oxygen ratio }<300 \\
\text { and/or lung infiltrates }>50 \% \text { within } 24- \\
48 \mathrm{~h}\end{array}$ \\
\hline Critical & $\begin{array}{c}\text { respiratory failure } \\
\text { septic shock } \\
\text { and/or multiple organ dysfunction or } \\
\text { failure }\end{array}$ \\
\hline
\end{tabular}

Table 3. CT grade system

\begin{tabular}{lc}
\hline Grade & Lung involvement \\
\hline 1 & $<5 \%$ \\
2 & $5-25 \%$ \\
3 & $26-49 \%$ \\
4 & $50-75 \%$ \\
5 & $>75 \%$ \\
\hline
\end{tabular}

\section{COVID-19 grading systems based on chest CT-scans}

Many, rather specific signs of COVID pneumonia have been recognised, using CT imaging, which can be of great importance when diagnosing and aiding the management of the disease.

CT-scans have a high sensitivity, but a lower specificity when determining the presence of COVID pneumonia [13]. However, it is important to emphasize, that a patient with PCR confirmed COVID-19 infection may have normal chest CT results at admission [14], while CT signs may appear even if the initial RT-PCR test was negative.

Characteristic findings are ground-glass opacity (GGO), GGO with consolidation, rounded opacities, crazy-paving pattern and air bronchograms. GGO's are multiple, round and commonly peripheral [15]. The term "crazy paving" was coined due to the polygonal pattern of interlobular thickening seen on scans [16].

In accordance with previous investigations, the severity of the disease correlates with the severity of lung involvement seen on the chest CT-scan. The grade is then calculated based on the involvement of the five lobes of the lung [17].

\section{Material and methods}

\section{Patients}

Between the $26^{\text {th }}$ of March and the $20^{\text {th }}$ of April 2020, 107 PCR confirmed SARS-CoV-2 infected patients were identified in Csongrád-Csanád county, Hungary. From this group, 52 symptomatic patients were admitted to hospital, because of comorbidities, older age (over 60 years) as well as people who were unable to isolate due to social status. 33 patients came from a cluster, a local nursing home.

The nursing home housed elderly, blind and psychiatric patients, as well as people who needed constant care due to a genetic or birth-related illness. Following the first identified COVID-19 patient, the residents were screened every two to four days.

This provided an opportunity to identify all infected individuals, examine the symptoms and clinical course of the disease in these individuals.

98 chest CT-scans were performed on 51 patients. The only excluding factor was age: no patient under 18 years was scanned, although our youngest infected patient at the time was 32 years old. In addition to age, gender and the onset of symptoms, information about contact and travel history was also collected.

\section{Image analysis}

All images were obtained on a 64-slice GE LightSpeed VCT XTe CT Scanner (General Electric - Fairfield, Connecticut, USA). All patients were in supine position during the examination. The main scanning parameters were as follows: tube voltage $=120 \mathrm{kVp}$, automatic tube current modulation slice thickness $=1.25 \mathrm{~mm}$. 
Image analysis was performed in accordance with the study of Shohei et al [18]. Parameters evaluated included first and foremost, the presence of ground-glass opacities, as well as consolidations, intra- or interlobular septal thickening, reversed halo sign and crazy-paving patterns.

The distributions of these patterns were evaluated by these categories: mostly peripheral, central or mixed distribution [18].

Ultimately, lung involvement was determined by subjectively identifying the above-mentioned patterns and abnormalities. This grading system proved to be suitable for comparison with the follow up CT scans. After determining the grade, we also searched for pleural effusion, lymphadenopathy (short axis greater than $10 \mathrm{~mm}$ ), airway abnormalities and any other lung pathology found, was recorded.

Two radiologists with different years of experience interpreted the scans, reviewing them separately to reach consensus. For each patient, the CT scan was evaluated for the following characteristics: 1 . presence of GGO, 2. presence of consolidation, 3 . the degree of involvement, 4. presence of pleural effusion, 5. presence of nodules, 6 . presence of thoracic lymphadenopathy (short axis $>10 \mathrm{~mm}$ ), 7. airway abnormalities (wall thickening, bronchiectasis) 8 . reverse halo sing, 9. crazy-paving pattern.

Figure 1 demonstrates the typical CT characteristics: image-A shows small peripheral GGO-s without consolidation, while image $\mathrm{B}-\mathrm{C}-\mathrm{D}$ shows the progression of the disease over time, with growing areas of GGO and consolidations appearing.

\section{Results}

\section{Demographic characteristics}

The mean age of the 51 patients examined was 67.94 year. Our youngest patient was 32, while the oldest was 94 years old. The male to female ratio was 1:2. 47 recovered, while 4 patients passed away. With one exception, all patients were treated at the coronavirus ward of the Epidemic Hospital, of the University of Szeged. The distribution of age, gender and outcome is collected in Table 4.

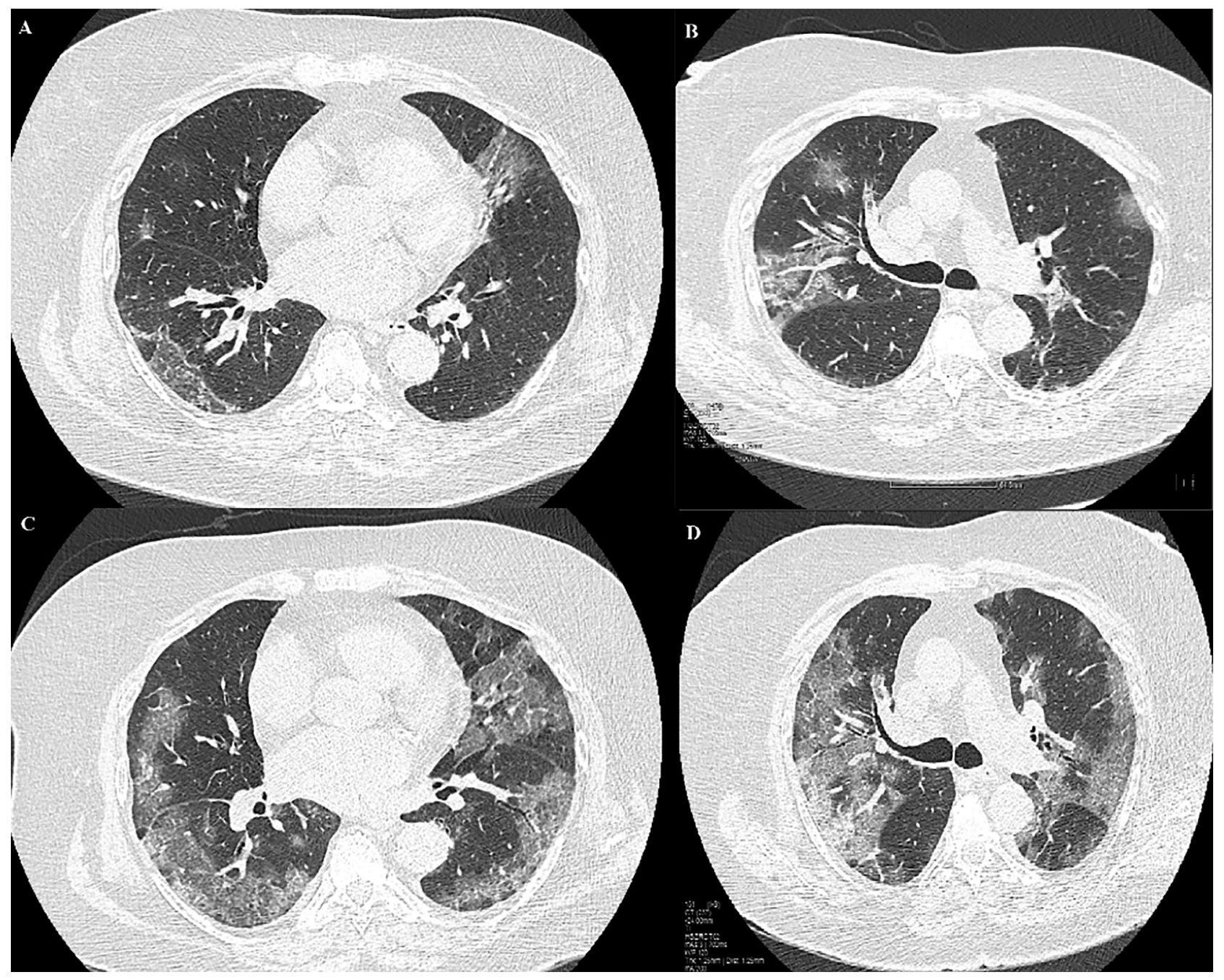

Fig. 1. Typical CT findings 
Table 4. Age, gender and outcome distribution

\begin{tabular}{lccc}
\hline All patients $(N=51)$ & & \\
\hline Age (years) & mean & \multicolumn{2}{c}{67.94} \\
& range & \multicolumn{2}{c}{$32-95$} \\
& standard deviation & & 12.74 \\
Gender & male & 17 & $33.33 \%$ \\
& female & 34 & $66.67 \%$ \\
Outcome & death & 4 & $7.80 \%$ \\
& recovered & 47 & $92.20 \%$ \\
\hline
\end{tabular}

Table 5. Comorbidity groups

\begin{tabular}{lr}
\hline Comorbidity groups & N \\
\hline Cardiovascular diseases & 50 \\
Psychiatric disorders & 29 \\
Neurological diseases & 22 \\
Endocrinopathia & 20 \\
Ophthalmic diseases & 11 \\
Tumours (any type) & 8 \\
Urological disease & 4 \\
Genetic diseases & 3 \\
Haematological diseases & 3 \\
Respiratory diseases & 3 \\
Chronic renal failure & 2 \\
Musculoskeletal disease (caused by & 1 \\
COVID infection) & \\
\hline
\end{tabular}

Table 6. Symptoms and signs

\begin{tabular}{lcrr}
\hline & Symptoms and signs & $\mathrm{N}$ & $\%$ \\
\hline Symtomps & dyspnoe & 12 & 23.53 \\
& cough & 6 & 11.76 \\
myalgia & 5 & 9.80 \\
weakness & 5 & 9.80 \\
diarrhea & 4 & 7.84 \\
headache & 4 & 7.84 \\
sore throat & 1 & 1.96 \\
anorexia & 1 & 1.96 \\
& nasal congestion & 1 & 1.96 \\
epipleptic seizure & 1 & 1.96 \\
digns & dizziness & 1 & 1.96 \\
& hypoxaemia & 26 & 50.98 \\
& altered mental status & 12 & 23.53 \\
fever $\left(\geq 38.3^{\circ} \mathrm{C}\right)$ & 7 & 13.73 \\
hypotension & 4 & 7.84 \\
\hline
\end{tabular}

The median comorbidity number is 3.32 . Due to the characteristics of the cluster originating in the nursing home, the most common comorbidities were hypertension, cerebrovascular disease, ischemic heart disease, diabetes mellitus, malignancies, epilepsy and schizophrenia (Table 5). Risk factors associated with more severe infectious disease progression, like autoimmune diseases and the use of immunemodulators were not present in our patient population.

\section{Symptoms and signs of COVID-19}

The more frequent symptoms of COVID-19 are listed in Table 6 . In contrast to previously published data, fever and dry cough were less common among our patients, whereas clinically detectable hypoxaemia and changes in the patients' mental status were much more indicative.

The higher proportion of asymptomatic patients and the fact that older age and psychiatric illnesses indirectly affected the perception of symptoms is the most likely explanation for these results. Furthermore, similarly to other COVID-19 patients, some less common manifestations were observed, eg. headache, vomiting and diarrhoea.

Table 7 contains the degree of lung involvement detected. Initial chest CT-s were negative or non-typical in $29.41 \%$ of cases.

Due to a higher percentage of comorbidities in the 33 patients from the nursing home (mental retardation and other cognitive dysfunctions), it was difficult to record a thorough medical and social history, as well as obtaining present complaints. Therefore, all residents had a CTscan performed, which showed pulmonary involvement of grade- 0 in $13(39.39 \%)$ and grade- 1 in 12 cases (36.36\%). 4 patients (12.12\%) with mild objective symptoms and no- or minimal need for oxygen supplementation were classified as grade-2. 3 patients $(9.09 \%)$ showed grade- 3 and only 1 patient $(3.03 \%)$ showed grade-4 lung involvement.

There was significant correlation between the CT grade and the clinical outcome $(P<0.001$, Cramer's $\mathrm{V}=0.581)$. If the initial CT grade is high, we may need to consider a worse clinical outcome and admission to an intensive care unit.

The other characteristic features are displayed in Table 8. In $70.97 \%$ of cases, the CT findings were bilateral, while the same percentage $(70.97 \%, n=22)$ were peripheral.

Four of the patients, two men and two women (average age: 77 years) died due to the infection, although they had

Table 7. Chest CT grades

\begin{tabular}{lcccc}
\hline Grade & First chest CT $(n=51)$ & Second chest CT $(n=31)$ & Third chest CT $(n=12)$ & Fourth chest CT $(n=4)$ \\
\hline $0^{*}$ & $15(29.41 \%)$ & $5(16.13 \%)$ & $1(8.33 \%)$ & $0(0 \%)$ \\
1 & $16(31.37 \%)$ & $5(16.13 \%)$ & $1(8.33 \%)$ & $2(50 \%)$ \\
2 & $11(21.57 \%)$ & $11(35.48 \%)$ & $6(50 \%)$ & $0(0 \%)$ \\
3 & $4(7.84 \%)$ & $6(19.35)$ & $3(25 \%)$ & $0(0 \%)$ \\
4 & $5(9.80 \%)$ & $3(29.03 \%)$ & $1(8.33 \%)$ & $2(50 \%)$ \\
5 & $0(0 \%)$ & $1(3.23 \%)$ & $0(0 \%)$ & $0(0 \%)$ \\
\hline
\end{tabular}

* - non-typical or negative. 
Table 8. Characteristic features on chest CT

\begin{tabular}{lcccc}
\hline & $\begin{array}{c}\text { Initial CT scan } \\
(n=51)\end{array}$ & $\begin{array}{c}\text { Second chest CT } \\
(n=31)\end{array}$ & $\begin{array}{c}\text { Third chest CT } \\
(n=20)\end{array}$ & $\begin{array}{c}\text { Fourth chest CT } \\
(n=4)\end{array}$ \\
\hline GGO & $38(\%)$ & $27(87.10 \%)$ & $14(70.00 \%)$ & $4(100 \%)$ \\
Consolidation & $18(\%)$ & $14(45.16 \%)$ & $11(55.00 \%)$ & $4(100 \%)$ \\
Pleural effusion & $7(\%)$ & $7(22.58 \%)$ & $6(30.00 \%)$ & $3(75 \%)$ \\
Lung nodule & $6(\%)$ & $5(16.13 \%)$ & $5(25.00 \%)$ & $2(50 \%)$ \\
Thoracic lymphadenopathy* & $9(\%)$ & $8(25.81 \%)$ & $5(25.00 \%)$ & $0(0 \%)$ \\
Bronchiectasia & $16(61.5 \%)$ & $12(38.71 \%)$ & $6(30.00 \%)$ & $2(50 \%)$ \\
Bronchial wall-thickening & $5(19.3 \%)$ & $4(12.90 \%)$ & $2(10.00 \%)$ & $1(25 \%)$ \\
Reverse halo sing & $3(11.5 \%)$ & $4(12.90 \%)$ & $1(5.00 \%)$ & $0(0 \%)$ \\
Crazypaving pattern & $2(7.7 \%)$ & $3(9.68 \%)$ & $2(10.00 \%)$ & $2(50 \%)$ \\
\hline
\end{tabular}

*short axis $>10 \mathrm{~mm}$.

comorbidities and severe lung involvement at the time of admission.

At first presentation, 36 patients were asymptomatic or had mild to moderate complaints according to the severity score. These patients did not need oxygen supplementation. 5 patients had severe or critical symptoms, such as high fever, dyspnoea and hypoxia - even though their chest CT showed less than $50 \%$ lung involvement. 4 patients were in critical status, respiratory failure and sepsis.

The distributions of CT scans according to the five-point grading system are presented in Table 3. 15 out of 51 (29.41\%) patients had normal or non-typical CT findings. Specific CT findings were more frequent with longer disease duration, including GGO and consolidation.

The initial CT grade and the clinical outcome show significant correlation (Spearman's rank correlation, rho = 0.6991 ), as a higher grade early on resulted in worse clinical status. Therefore, it's advised, that these patients are monitored fore frequently (blood tests, imaging if necessary), so that the proper care can be provided, if their condition starts to deteriorate.

Four of the patients, two male and two female with comorbidities were admitted in very serious conditions. Massive lung manifestations (GGO, consolidation) were confirmed on the first CT-scans.

There was one male patient, whose respiratory parameters go worse over time, even though his initial CT-scan was negative. The clinical status followed the severity of lung involvement.

\section{Laboratory signs}

The most common indicator was an increase in serum CRP and LDH levels. In addition, thrombocytopenia, lymphopenia, eosinopenia, and monocytosis were observed in the complete blood count. The blood test results are summarized in Table 9.

A significantly higher progression in the clinical status was detectable, when a patient's initial blood test showed elevated levels of blood urea nitrogen (UN) $(P<0.001$, Cramer's $\mathrm{V}=0.488)$ and $\mathrm{LDH}(P<0.001$, Cramer's $\mathrm{V}=$ 0.537). Accordingly, CT examinations may need to be performed more frequently in this population.

\section{Clinical stages and outcome of patients}

At admission, 14 (27.45\%) patients were asymptomatic, 3 (5.88\%) were mildly symptomatic, 29 (56.86\%) were moderate, $4(7.84 \%)$ were severe and $1(1.96 \%)$ was critically ill (Table 10).

Furthermore, in $8(15.69 \%)$ patients, the disease progressed. 2 asymptomatic and 1 in a mild clinical stage progressed to moderate. 2 moderately severe patients became severely clinical. 3 severe patients became critically ill. Later, all severely ill patients and 2 critically ill patients were admitted to the intensive care unit (Table 11).

All patients reaching the critical stage, regardless of whether they received invasive respiratory support and intensive therapy, have passed away. The calculated mortality rate for the region was $3.74 \%$ and $7.84 \%$ patients were hospitalized (Table 12).

There was a significant correlation between Mulbsta score (viral pneumonia mortality score) and the clinical progression (Two sample $T$-test, $P$-value $=0.0459$ ). The Mulbsta score varied between the two groups of patients, whose clinical state progressed with time and those who remained stable.

\section{Discussion}

It seems, that the Hungarian population were effected less by the COVID-19 pandemic than other European countries. The observed patients in our hospitals have shown similar symptoms in accordance with the previous studies. No evidence-based reason was found for the low incidence of COVID-19 pneumonia in our region.

We can conclude, that the CT report and grading system reflected the patients' clinical condition and need for oxygen supplementation.

We also found a difference in prevalence between genders, with a 1:2 ratio of men to women. The highest incidence was between 60 and 70 years of age. Interestingly, correlating with other studies, male patients seem to be more at risk for worse outcomes [19]. Our study has limitations due to the low number of patients. 
Table 9. Laboratory parameters

\begin{tabular}{|c|c|c|c|c|c|c|}
\hline Parameters & & Range & & Total number & Number & Percent (\%) \\
\hline \multicolumn{7}{|l|}{ Minerals } \\
\hline \multicolumn{7}{|l|}{ Sodium } \\
\hline & $>$ & 145.00 & $\mathrm{mmol} / \mathrm{L}$ & 49 & 4 & 8.16 \\
\hline & $<$ & 136.00 & $\mathrm{mmol} / \mathrm{L}$ & 49 & 9 & 18.37 \\
\hline \multicolumn{7}{|l|}{ Potassium } \\
\hline & $>$ & 5.20 & $\mathrm{mmol} / \mathrm{L}$ & 49 & & 0.00 \\
\hline & $<$ & 3.50 & $\mathrm{mmol} / \mathrm{L}$ & 49 & 3 & 6.12 \\
\hline \multicolumn{7}{|l|}{ Cardiac biomarkers } \\
\hline $\mathrm{LDH}$ & $>$ & 190.00 & $\mathrm{U} / \mathrm{L}$ & 42 & 25 & 59.52 \\
\hline $\mathrm{CK}$ & $>$ & 170.00 & $\mathrm{U} / \mathrm{L}$ & 34 & 12 & 35.29 \\
\hline CK-MB & $>$ & 25.00 & $\mathrm{ng} / \mathrm{mL}$ & 8 & 5 & 62.50 \\
\hline Troponin- $\mathrm{T}$ & $>$ & 0.04 & ug/L & 23 & 3 & 13.04 \\
\hline \multicolumn{7}{|l|}{ Comprehensive metabolic panel } \\
\hline AST & $>$ & 37.00 & $\mathrm{U} / \mathrm{L}$ & 42 & 7 & 16.67 \\
\hline ALT & $>$ & 40.00 & $\mathrm{U} / \mathrm{L}$ & 42 & 7 & 16.67 \\
\hline Bilirubin & $>$ & 21.00 & $\mathrm{umol} / \mathrm{L}$ & 42 & 1 & 2.38 \\
\hline BUN & $>$ & 11.10 & $\mathrm{mmol} / \mathrm{L}$ & 48 & 3 & 6.25 \\
\hline Creatinin & $>$ & 115.00 & $\mu \mathrm{mol} / \mathrm{L}$ & 48 & 3 & 6.25 \\
\hline \multicolumn{7}{|l|}{ Other parameter } \\
\hline D-dimer & $>$ & 0.50 & $\mathrm{ug} / \mathrm{mL}$ & 18 & 11 & 61.11 \\
\hline Ferritin & $>$ & 400.00 & & 10 & 2 & 20.00 \\
\hline \multicolumn{7}{|l|}{ Inflammatory parameters } \\
\hline CRP & $>$ & 5.00 & $\mathrm{mg} / \mathrm{L}$ & 50 & 38 & 76.00 \\
\hline PCT & $>$ & 0.50 & $\mathrm{ng} / \mathrm{mL}$ & 26 & & 0.00 \\
\hline \multicolumn{7}{|l|}{ Full blood count } \\
\hline & $>$ & 11.10 & $\mathrm{G} / \mathrm{L}$ & 50 & 5 & 10.00 \\
\hline & $<$ & 3.70 & $\mathrm{G} / \mathrm{L}$ & 50 & 8 & 16.00 \\
\hline \multicolumn{7}{|l|}{ Absolute neutorphil count } \\
\hline & $>$ & 7.50 & $\mathrm{G} / \mathrm{L}$ & 48 & 7 & 14.58 \\
\hline & $<$ & 1.70 & $\mathrm{G} / \mathrm{L}$ & 48 & 3 & 6.25 \\
\hline \multicolumn{7}{|l|}{ Absolute lymphocyte count } \\
\hline & $>$ & 3.20 & $\mathrm{G} / \mathrm{L}$ & 48 & & 0.00 \\
\hline & $<$ & 1.00 & $\mathrm{G} / \mathrm{L}$ & 48 & 15 & 31.25 \\
\hline \multicolumn{7}{|l|}{ Absolute monocyta count } \\
\hline & $>$ & 0.60 & $\mathrm{G} / \mathrm{L}$ & 48 & 16 & 33.33 \\
\hline & $<$ & 0.20 & $\mathrm{G} / \mathrm{L}$ & 48 & & 0.00 \\
\hline \multicolumn{7}{|l|}{ Absolute eosinophil count } \\
\hline & $>$ & 0.60 & $\mathrm{G} / \mathrm{L}$ & 48 & & 0.00 \\
\hline & $<$ & 0.03 & $\mathrm{G} / \mathrm{L}$ & 48 & 23 & 47.92 \\
\hline \multicolumn{7}{|l|}{ Thrombocyta count } \\
\hline & $>$ & 358 & $\mathrm{G} / \mathrm{L}$ & 49 & 3 & 6.12 \\
\hline & $<$ & 169 & $\mathrm{G} / \mathrm{L}$ & 49 & 16 & 32.65 \\
\hline \multicolumn{7}{|l|}{ Haemoglobin } \\
\hline & $>$ & 148 & $\mathrm{~g} / \mathrm{L}$ & 50 & 5 & 10.00 \\
\hline & $<$ & 118 & $\mathrm{~g} / \mathrm{L}$ & 50 & 14 & 28.00 \\
\hline \multirow[t]{2}{*}{ Mean corpuscular volume (MCV) } & $>$ & 98.00 & $\mathrm{fl}$ & 50 & 2 & 4.00 \\
\hline & $<$ & 82.00 & $\mathrm{fl}$ & 50 & 8 & 16.00 \\
\hline
\end{tabular}

Table 10. At first detection, the COVID-19 stage

\begin{tabular}{lrrcrr}
\hline & $\mathrm{N}$ & \multicolumn{1}{c}{$\%$} & Average age & Comorbidity & Male: female \\
\hline Asymptomatic & 14 & 27.45 & 69.07 & 3.14 & $1: 6$ \\
Mild & 3 & 5.88 & 62.67 & 4.33 & $1: 2$ \\
Moderate & 29 & 56.86 & 66.59 & 3.14 & $1: 42$ \\
Severe & 4 & 7.84 & 82 & 4 & $1: 3$ \\
Critical & 1 & 1.96 & 80 & 4 & $1: 0$ \\
\hline
\end{tabular}


Table 11. The most severe stage in the observation of patients

\begin{tabular}{lrrccc}
\hline & $\mathrm{N}$ & $\%$ & Average age & Comorbidity & Male:Female \\
\hline Asymptomatic & 12 & 23.53 & 67.92 & 3.33 & $1: 5$ \\
Mild & 2 & 3.92 & 58.5 & 3.5 & $1: 1$ \\
Moderate & 30 & 58.82 & 66.9 & 3.17 & $1: 1.73$ \\
Severe & 3 & 5.88 & 81.67 & 2.67 & $1: 2$ \\
Critical & 4 & 7.84 & 85 & $1: 1$ \\
\hline
\end{tabular}

Table 12. Clinical staging of all SARS-CoV-2 infected patients in our region

\begin{tabular}{lrr}
\hline & $\mathrm{N}$ & \multicolumn{1}{c}{$\%$} \\
\hline Asymptomatic & 68 & 63.55 \\
Mild & 2 & 1.87 \\
Moderate & 30 & 28.04 \\
Severe & 3 & 2.80 \\
Critical & 4 & 3.74 \\
\hline
\end{tabular}

Research suggests that the most common characteristic CT finding is GGO, which is consistent with our observations. GGO usually presents in bilateral, basal, peripheral and multifocal localisation, commonly in the inferior lobe of the right lung. GGO, along with crazy paving pattern, bronchiectasis and enlarged vessels were also noted.

Numerous studies suggest that chest $\mathrm{X}$-rays are not suitable for sufficient evaluation of the grade of infection. In our institution, only four positive patients had a chest X-ray performed.
In these occurrences, the patients were not suspected of having COVID-19 initially, therefore the X-ray preceded a CT-scan and a PCR test in each case. Figures 2 and 3 show the comparison between the X-ray and the CT images of two patients.

It is clear, that the X-ray could not provide enough information about the severity of the lung involvement.

Considering the fact, that every patient from the cluster and the majority of other positive patients were most likely infected by local transmission, while contact research was generally unsuccessful, a wider population screening for asymptomatic patient was no performed. According to the WHO database, approximately $80 \%$ of COVID-19 infections are asymptomatic, or mildly symptomatic (eg. subfebrility) [20]. Therefore, we can assume with confidence that the regional mortality rate gives an overestimation of the true value.

These results go beyond previous reports, showing that some of the examined laboratory data, like LDH and UN levels in the blood correlate closely with the grade of pneumonia seen on the scans [21]. High levels of LDH may indicate tissue damage and the severity of sepsis, which would

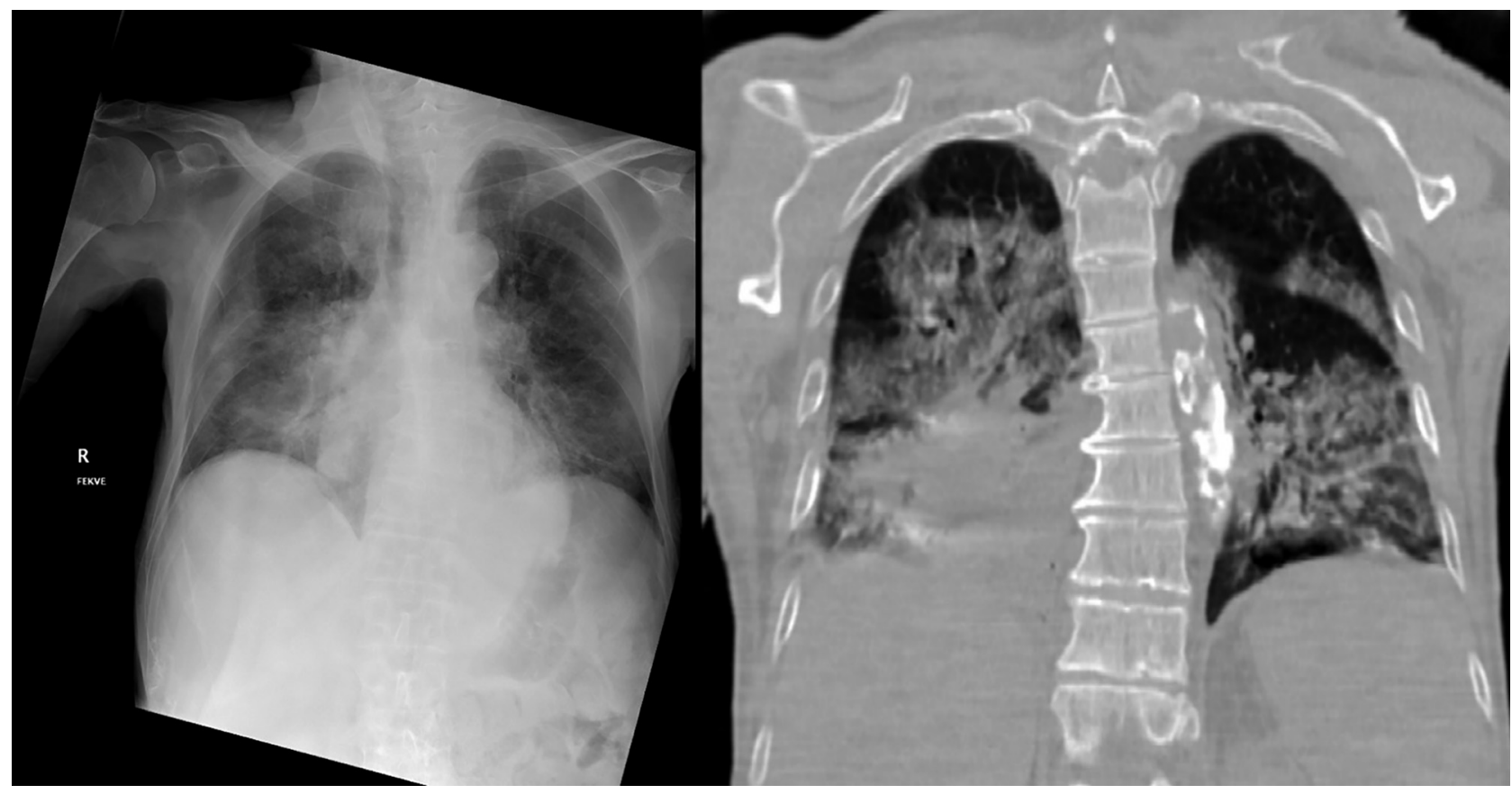

Fig. 2. 84 years old male patient. After a trauma he was admitted to the orthopaedic ward for hip replacement operation. After a several days the patient body temperature was elevated. On the chest X-ray there were right side dominant, bilateral opacities. On the following day chest CT was performed, which showed bilateral ground-glass opacities and consolidation. The lung involvement, however was only Grade2 


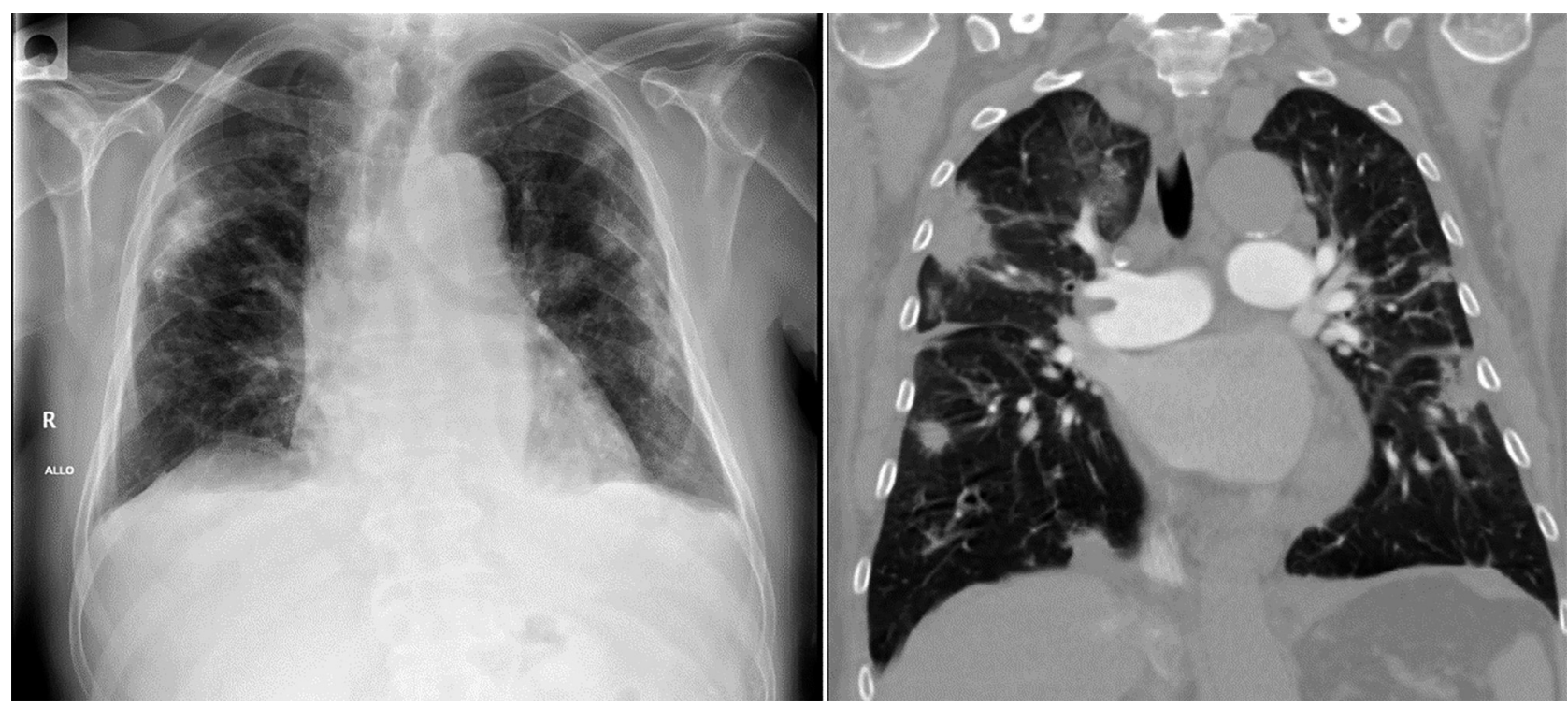

Fig. 3. A 60 year old male patient was admitted to the emergency department with non-specific symptoms, such as general weakness. Chest $\mathrm{X}$-ray was performed to rule out any chest pathology. On the X-ray bilateral rounded opacities were found, based on which RT-PCR test was requested that proved COVID-19 infection. On the chest CT bilateral extended consolidation was seen, the lung involvement was Grade 4

explained the associations between the two tests [22]. The elevated UN level also reflects the severity of the disease [23].

Regarding our limitations with a lower count of COVID19 pneumonia cases, it could be argued that laboratory and chest CT finding are similar to that of other studies. It is a question for future research to investigate, why the Hungarian population was less effected, despite using the same epidemiologic regulations as other European countries.

\section{Summary}

Native chest CT examinations are essential in the planning of management and treatment. Review of the literature shows, that the grade determined from a chest CT closely correlates with mortality [24]. The grading system used by us, corresponded well with the patients' clinical status and oxygen demand. In cases, when large lung involvement was seen on the first CT scan ( $>50 \%$, grade- 4$)$, the patient died despite intensive care treatment.

Keeping in mind the obvious limitations of our results, due to the low morbidity in Hungary, we found it is advisable to perform chest CT-s more frequently on patients with higher levels of $\mathrm{LDH}$ and blood UN at the time of admission, as the likelihood of a higher CT grade and therefore mortality increases with those values.

Every patient deemed grade- 4 was admitted to the intensive care unit and eventually needed respiratory support. According to the recommendations, if the symptoms and oxygen supplementation demand remained unchanged and signs of regression were not detected, the chest CT scan was repeated after five to seven days. If the infected patient's status progressed, or the clinicians considered it necessary, the CT was repeated after two or three days.
Funding information: The authors state that this work has not received any funding.

\section{ABBREVIATION}

ACE2

COVID-19

CT

GGO

$\mathrm{LDH}$

MERS-CoV

PCR

RT-PCR

SARS-CoV

SARS-CoV-2 Severe Acute Respiratory Syndrome Coronavirus 2

sgRNA messenger RNA

UN urea nitrogen

WHO World Health Organization

\section{REFERENCES}

[1] Team TNCPERE: The epidemiological characteristics of an outbreak of 2019 novel coronavirus diseases (COVID-19) China, 2020. China CDC Weekly 2020; 2(8): 113-22. https://doi. org/10.46234/CCDCW2020.032.

[2] Cui J, Li F, Shi ZL: Origin and evolution of pathogenic coronaviruses. Nat Rev Microbiol 2019; 17(3): 181-92. https://doi.org/10. 1038/s41579-018-0118-9. 
[3] Tay MZ, Poh CM, Rénia L, MacAry PA, Ng LFP: The trinity of COVID-19: immunity, inflammation and intervention. Nat Rev Immunol 2020: 1-12. https://doi.org/10.1038/s41577-020-0311-8.

[4] Chan J-W, Kok K-H, Zhu Z, Chu H, Kai Wong To H, Yuan S: Genomic characterization of the 2019 novel human-pathogenic coronavirus isolated from a patient with atypical pneumonia after visiting Wuhan. Emerg Microbes Infect 2020; 9(1): 221-36. https:// doi.org/10.1080/22221751.2020.1719902.

[5] WHO Director-General's opening remarks at the media briefing on COVID-19 - 11 March 2020. https://www.who.int/dg/ speeches/detail/who-director-general-s-opening-remarks-at-themedia-briefing-on-covid-19-11-march-2020. Accessed May 22, 2020.

[6] Zhou J, Li C, Liu X, Chu M, Zhao X, Wang D: Infection of bat and human intestinal organoids by SARS-CoV-2. Nat Med May 2020; 1-7. https://doi.org/10.1038/s41591-020-0912-6.

[7] Wölfel R, Corman V, Guggemos W, Zange S, Müller M, Niemeyer D: Virological assessment of hospitalized patients with COVID2019. Nature April 2020; 1-5. https://doi.org/10.1038/s41586-0202196-x.

[8] Li Q, Guan X, Wu P, Zhou L, Tong Y, Ren R: Early transmission dynamics in Wuhan, China, of novel coronavirus-infected pneumonia. N Engl J Med 2020; 382(13): 1199-207. https://doi.org/10. 1056/NEJMoa2001316.

[9] Goyal P, Choi J, Pinheiro L, Schenck E, Chen R, Jabri A: Clinical characteristics of covid-19 in New York city. N Engl J Med 2020; 382(24): 2372-4. https://doi.org/10.1056/NEJMc2010419.

[10] Lechien J, Chiesa-Estomba C, Place S, Leathem Y, Cabaraux P, Mat Q: Clinical and epidemiological characteristics of $1420 \mathrm{Eu}-$ ropean patients with mild-to-moderate coronavirus disease 2019 [published online ahead of print, 2020 Apr 30]. J Intern Med 2020. https://doi.org/10.1111/joim.13089.

[11] Wu Z, McGoogan JM: Characteristics of and important lessons from the coronavirus disease 2019 (COVID-19) outbreak in China: summary of a report of 72314 cases from the Chinese center for disease control and prevention. JAMA - J Am Med Assoc 2020; 323(13): 1239-42. https://doi.org/10.1001/jama.2020.2648.

[12] Minisztériuma EE. A 2020. Évben Azonosított Új Koronavírus (SARS-CoV-2) Okozta Fertőzések (COVID-19) Megelőzésének És Terápiájának Kézikönyve, Vol 25.

[13] Zhou S, Wang Y, Zhu T, Xia L: CT features of coronavirus disease 2019 (COVID-19) pneumonia in 62 patients in Wuhan, China.
AJR Am J Roentgenol 2020; 214(6): 1287-94. https://doi.org/10. 2214/AJR.20.22975.

[14] Yang W, Yan F: Patients with RT-PCR-confirmed COVID-19 and normal chest CT. Radiology 2020; 295(2): E3. https://doi.org/10. 1148/radiol.2020200702.

[15] Ojha V, Mani A, Pandey NN, Sharma S, Kumar S: CT in coronavirus disease 2019 (COVID-19): a systematic review of chest CT findings in 4410 adult patients. Eur Radiol 2020: 1-10. Advance online publication. https://doi.org/10.1007/s00330-020-06975-7.

[16] Verma R, Abdoh M: Crazy paving pattern. Clin Case Rep 2017; 5(4): 533-4. Published 2017 Feb 21. https://doi.org/10.1002/ccr3. 860.

[17] Salehi S, Abedi A, Balakrishnan S, Gholamrezanezhad A: Coronavirus disease 2019 (COVID-19): a systematic review of imaging findings in 919 patients. AJR Am J Roentgenol 2020; 215(1): 87-93. https://doi.org/10.2214/AJR.20.23034.

[18] Inui S, Fujikawa A, Jitsu M, Kunishima N, Watanabe S, Suzuki Y, et al.: Chest CT findings in cases from the cruise ship "diamond princess" with coronavirus disease 2019 (COVID-19). Radiol Cardiothorac Imaging 2020; 2(2): e200110. https://doi.org/10. 1148/ryct.2020200110.

[19] Jin JM, Bai P, He W, WU F, Liu XF, Han DM: Gender differences in patients with COVID-19: focus on severity and mortality. Front Public Health 2020; 8: 152. Published 2020 Apr 29. https://doi.org/ 10.3389/fpubh.2020.00152.

[20] Coronavirus disease 2019 (COVID-19) situation report - 46. Retrieved from https://www.who.int/docs/default-source/ coronaviruse/situation-reports/20200306-sitrep-46-covid-19.pdf? sfvrsn=96b04adf_ 4 .

[21] Lippi G, Plebani M: Laboratory abnormalities in patients with COVID-2019 infection. Clin Chem Lab Med 2020; 58(7): 1131-4. https://doi.org/10.1515/cclm-2020-0198.

[22] Henry B, Aggarwal G, Wong J, Benoit S, Vikse J, Plebani M, Lippi G: Lactate dehydrogenase levels predict coronavirus disease 2019 (COVID-19) severity and mortality: a pooled analysis. 2020 May 27. Retrieved from https://www.sciencedirect.com/science/article/ pii/S0735675720304368.

[23] Cheng Y, Luo R, Wang K, Zhang M, Wang Z, Dong L: Kidney disease is associated with in-hospital death of patients with COVID-19. Kidney Int 2020; 97(5): 829-38.

[24] Kerpel-Fronius A, Solymosi D: Imaging of COVID-19 pneumonia. Initial Experiences MRO 2020; 11: 2/1-5. 